\title{
Health Literacy, Processing Capacity, Illness Knowledge, and Actionable Memory for Medication Taking in Type 2 Diabetes: Cross-Sectional Analysis
}

Jessie Chin, Ph. D. ' (D, Huaping Wang, Ph. D. ${ }^{2}$, Adam W. Awwad, MS. ${ }^{2}$,

James F. Graumlich, M.D. ${ }^{2}$, Michael S. Wolf, Ph.D. ${ }^{3}$, and Daniel G. Morrow, Ph. D. ${ }^{1}$

'University of Illinois at Urbana-Champaign, Champaign, IL, USA; ${ }^{2}$ University of Illinois College of Medicine in Peoria, Peoria, IL, USA; ${ }^{3}$ Northwestern University Feinberg School of Medicine, Chicago, IL, USA.

BACKGROUND: Patient knowledge about the purpose of medications is crucial to ensure safe and correct use, so it is an important index of adherence in patients with chronic illness.

OBJECTIVE: We examined how health literacy and its components (processing capacity and knowledge about illness) influence memory for medication purposes.

DESIGN: We conducted a cross-sectional study to examine memory for medication purposes in relation to health literacy, processing capacity, and illness knowledge among patients with diabetes in outpatient clinics.

PARTICIPANTS: Six hundred seventy-four adults who were diagnosed with type II diabetes mellitus, age 40 years or older, taking 5 or more current medications, native speakers of English, and with glycosylated hemoglobin (HbAlc) of 6.0 or more, were recruited to the study.

MAIN MEASURES: We included measures of processing capacity, illness knowledge, health literacy, and actionable memory for medication taking (memory for medication purpose).

KEY RESULTS: Results suggested an association between health literacy and both processing capacity and health knowledge, with some evidence that knowledge can compensate for limited processing capacity in order to maintain health literacy. Furthermore, health literacy was associated with memory for medication purposes, with processing capacity and health knowledge partly mediating this association. This pattern of results supports the process-knowledge model of health literacy.

CONCLUSIONS: Our findings establish the role of health literacy in medication taking, in relation to broader cognitive abilities and knowledge. Implications for improving the learning of medication purpose among diverse older adults with chronic illness are discussed.

TRIAL REGISTRATION: NIH trial registry number: NCT01296633

KEY WORDS: health literacy; memory for medication purpose; medication schemas; illness knowledge; diabetes.

Received June 14, 2020

Accepted December 14, 2020

Published online January 28, 2021
J Gen Intern Med 36(7):1921-7

DOI: $10.1007 / \mathrm{s} 11606-020-06472-\mathrm{z}$

(C) Society of General Internal Medicine 2021

\section{INTRODUCTION}

Patients' knowledge about their medication is important for medication adherence and health outcomes (such as glucose levels, A1C). ${ }^{1-4}$ More generally, patients' perceptions about medications and illness are associated with adherence. ${ }^{5,6} \mathrm{Med}-$ ication knowledge is a broad construct encompassing several kinds of understanding. Correct medication use requires procedural knowledge, which can be conceptualized as a mental model, or schema, that organizes knowledge about the steps and conditions required to accomplish the task. Older and younger adults share a schema for taking medication composed of identifying information (medication name, purpose), how to take (e.g., dose, times to take, warnings), and possible outcomes (e.g., side-effects). ${ }^{7,8}$

The purpose for taking medication is central to medication schemas and generating actionable knowledge by helping patients understand the goals associated with taking the medication as part of self-care, thereby helping to integrate the components of the schema. Understanding medication purpose is critical for managing complex regimens. For example, patients can group multiple medications according to their common purpose. Indeed, patients who know more about the purpose of their medications are more likely to take medications as prescribed. ${ }^{9}$ Similarly, older and younger adults better remember appointment reminder messages that include the reason for the appointment, perhaps because this information helps organize memory for executing actions. ${ }^{10}$ Unfortunately, patients often do not know or remember the purpose of their medications, in part because this information is rarely on medication container labels. ${ }^{11}$ Patients who do not understand or remember the purpose of the medications may be less likely to see their need and to take them, especially in the context of complex regimens typical of diabetes. ${ }^{3,12}$

We investigated determinants of memory for medication purpose among adults with type II diabetes, focusing on health 
literacy. Health literacy, defined as the ability to obtain, process, and understand health information for making healthrelated decisions, ${ }^{13}$ is associated with medication knowledge, ${ }^{14}$ adherence, and health outcomes. ${ }^{14-18}$ According to the process (capacity)-knowledge model (P-K model), health literacy reflects the interplay of broader cognitive abilities (Fig. 1). ${ }^{19}$ In support of this model, we demonstrated the association between performance on the Short Test of Functional Health Literacy in Adults (STOFHLA) and recall of information needed for self-care among older adults with hypertension. This association was mediated by processing capacity and knowledge (both general and domain-specific knowledge about hypertension). ${ }^{19-21}$

The P-K model also suggests processing capacity and knowledge interact to influence understanding of and memory for self-care information because these abilities tend to have different influences on comprehension and differing agerelated trajectories. Knowledge often facilitates comprehension and tends to be relatively unchanged with age in adulthood, while processing capacity limitations constrain comprehension and often decline with age, thereby exacerbating limitations. Therefore, knowledge may help offset the influence of processing capacity limits on comprehension and memory. ${ }^{19,20}$ The current study examined how health literacy and its components (processing capacity and illness knowledge ) influence memory for medication purpose, a critical but under-studied facet of medication schemas.

\section{METHOD}

\section{Design and Setting}

The study design was cross-sectional. The data were from participants in a randomized, controlled, clinical trial (RCT) (details about the RCT design ${ }^{22}$ ). The present paper is an analysis of data collected at the study baseline, prior to the randomized intervention. The trial was conducted among two outpatient primary care internal medicine clinics in Chicago and Peoria, Illinois. The institutional review boards of
Northwestern University and the University of Illinois approved and monitored the research.

\section{Participants}

The inclusion criteria for study participant enrollment were diagnosis of type II diabetes mellitus, age 40 years or older, 5 or more current medications, native speaker of English, and glycosylated hemoglobin (HbA1c) 6.0 or more. Exclusion criteria were physical or cognitive impairments (e.g., stroke in the last 3 years, current cancer treatment with radiation or chemotherapy), score of 4 or more errors on the short screen for dementia, ${ }^{23}$ visual impairment (corrected vision less than 20/50), or auditory impairment.

Research personnel administered a modified version of the Older Americans Resources and Services instrument to ascertain age, gender, education, and race/ethnicity. ${ }^{24}$

\section{Procedure}

Participant recruitment and enrollment occurred from September 2011 to October 2013. Research personnel (RP) received permission from primary care physicians and practitioners to screen medical records to identify potential participants who met inclusion criteria. Next, RP performed telephone interviews to assess inclusion/exclusion criteria, determine eligibility, and start the informed consent process. If the interviewee agreed, RP scheduled the baseline research visit to coincide with the next clinic visit with the primary care clinician. Participants received instructions to bring all their medications to the visit in their original, labeled containers. During the visit, RP documented informed consent, recorded responses to verbal questions (e.g., number of years since diagnosis of diabetes), and administered survey instruments. They recorded drug names from the label on every container as well as the total number of drugs for each participant.

\section{Measures}

Measure of Self-Care: Actionable Memory for Medication

Taking. We ascertained memory for the indication or purpose

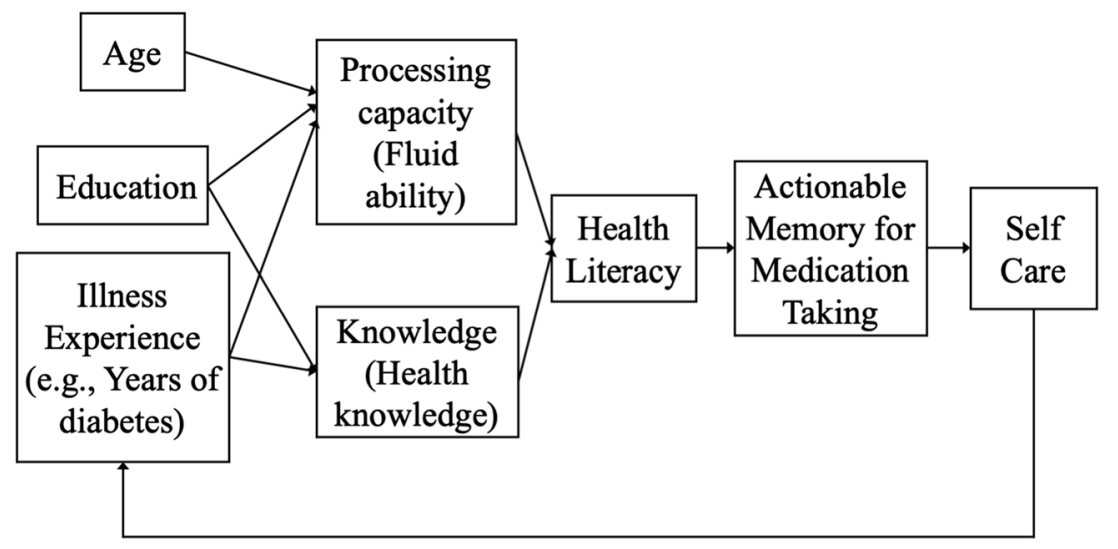

Figure 1 Conceptual model (adapted from Chin et al. 2011). 
for each medicine in the participant's regimen. RP recorded the individual's verbatim response to the following question: "What is the medicine for?" Scoring of the responses was blinded. Two board-certified internal medicine physicians independently adjudicated the response for every medication in the regimen. The adjudicators had no contact with participants or RP. There was substantial agreement between the adjudicators (Cohen's kappa was 0.74). After the initial review, the adjudicators reviewed all discordant scores and resolved discrepancies. For analysis, the investigators calculated the mean number of correctly remembered medication purposes in the regimen: the number of medication purposes scored as correct divided by the total number of medications in the regimen.

Health Literacy. Health literacy was measured by the REALM (Rapid Estimate of Adult Literacy in Medicine). ${ }^{25}$ RP asked participants to pronounce 66 health terms that varied in difficulty and frequency. The number of correctly pronounced words was the measure of health literacy. There is also a grade-level equivalent classification in REALM. People who score lower than 61 are considered to have limited health literacy. People who score lower than $18\left(3^{\text {rd }}\right.$ grade and below) would not be able to read most lower literacy materials. People who score 19-44 ( $4^{\text {th }}$ to $6^{\text {th }}$ grade) would not be able to read prescription labels. People who score 45 to $60\left(7^{\text {th }}\right.$ to $8^{\text {th }}$ grade) would struggle with most patient education materials. ${ }^{25}$

\section{Health Literacy-Related Abilities: Processing Capacity and} Health Knowledge. Processing capacity (PC) was measured by the Letter Comparison and Pattern Comparison tests, commonly used to evaluate individual differences in processing speed in aging research. ${ }^{26}$ The composite score of the standardized scores from Letter and Pattern comparison tests $(r=$ $0.66, p<.001$ ) was used as the measure of PC.

Knowledge about diabetes (HK; health knowledge) was measured with a 24-item true and false knowledge questionnaire (DKQ-24; Cronbach alpha 0.73 0.84). ${ }^{27}$ Questions assessed different facets of knowledge, including diet, medication, interpretation of clinical results, and physiological mechanisms. The average score was calculated (mean = $18.67, \mathrm{SD}=2.92$ ).

\section{Sample Size}

The size of the cross-sectional study was a convenience sample of the 674 participants with baseline data from the RCT. ${ }^{22}$ For purposes of post hoc analysis, the investigators made the following assumptions about the sample size.

The effect of health literacy on PC or HK was small and accounted for $2 \%$ of total variance according to Cohen's criteria for small effect size. ${ }^{28}$ The effect of PC or HK on medication purpose was also small and accounted for $2 \%$ of the total variance. With these assumptions, the power to detect a significant mediation effect was $80 \%$. Using the bias- corrected bootstrap method to estimate sample size, ${ }^{29}$ the required number of subjects was 462 . The sample with baseline data (674 participants) indicated sufficient power to perform tests related to mediation.

\section{Statistical Methods}

We first explored the relationships among health literacy, PC, $\mathrm{HK}$, and memory for medication purposes using simple correlations to examine whether the pattern was consistent with the P-K model. We then conducted multiple linear regressions to examine associations among the components of health literacy. Multiple linear regression and a parallel multiple mediator model with two mediators were next conducted to test whether the effects of health literacy on memory for medication purposes could be accounted for by PC and HK, as predicted by our P-K model. All measures were standardized to minimize the collinearity.

\section{RESULTS}

The investigators screened 3644 people for eligibility. From the screened population, 502 people were not eligible according to the inclusion or exclusion criteria, 2414 declined to participate, and 54 were excluded for other reasons. The remaining 674 participants were included in the analysis (55.2\% female; mean age $=63.6, \mathrm{SD}=10.10$ ). Participants' mean number of prescribed medications was $7.23(\mathrm{SD}=2.84)$. The average year of diabetes was 12.5 years ( $\mathrm{SD}=9.47$, range: $1-50$ years). Longer illness duration was associated with greater $\mathrm{HK}(r=0.13, p<$ $.001)$. About two-thirds of participants had more than high school education. The sample was composed of $29.2 \%$ African American, 65.6\% Caucasian, 1.9\% Hispanic or Latino, 0.9\% Asian, and $2.1 \%$ other racial groups. Following the gradeequivalent classification in REALM, there were 7 patients whose levels of literacy were $3^{\text {rd }}$ grade and below; 32 patients whose levels of literacy were $4^{\text {th }}$ to $6^{\text {th }}$ grade; and 111 patients whose levels of literacy were $7^{\text {th }}$ to $8^{\text {th }}$ grade. A total of 150 patients had inadequate health literacy and would struggle with reading prescriptions and patient education materials. With $22.26 \%$ of patients with inadequate health literacy, our findings could be generalized to other patients with inadequate health literacy. The average accuracy score of memory for medication purposes was $0.87(\mathrm{SD}=0.21)$.

\section{Correlations}

The pattern of associations in Table 1 is consistent with the literature, with age negatively related to $\mathrm{PC}$ and a smaller association with HK. Given that PC declines with age ${ }^{30}$, and the acquisition of domain-specific knowledge (e.g., illness, medication) is affected by the decline in PC as we age ${ }^{31}$, the age-related negative associations with $\mathrm{PC}, \mathrm{HK}$, and MP are expected. The pattern is also consistent with the P-K model: Health literacy was positively associated with PC, HK, and 
Table 1 Descriptive Statistics and Correlations among Age, Education (Edu), Processing Capacity (PC), Health Knowledge (HK), Health Literacy (HL), and Memory for Medication Purpose (MP)

\begin{tabular}{|c|c|c|c|c|c|c|}
\hline & Mean (SD) & Edu & $\mathbf{P C}$ & HK & HL & MP \\
\hline Age & $63.61(10.13)$ & -.0 .03 & $-0.34 * *$ & $-0.11 * *$ & 0.04 & $-0.20 * *$ \\
\hline Education & $4.93(0.94)$ & & $0.25 * *$ & $0.18 * *$ & $0.44 * *$ & $0.14 * *$ \\
\hline Letter comparison & $17.17(4.96)$ & & & & & \\
\hline Pattern comparison & $29.07(7.79)$ & & & & & \\
\hline $\mathrm{PC}$ & & & & $0.25 * *$ & $0.31 * *$ & $0.24 * *$ \\
\hline $\mathrm{HK}(\max =24)$ & $18.66(2.92)$ & & & & $0.25 * *$ & $0.26 * *$ \\
\hline $\mathrm{HL}(\max =66)$ & $61.19(8.87)$ & & & & & $0.20 * *$ \\
\hline MP & $0.87(0.21)$ & & & & & \\
\hline
\end{tabular}

$* * p<.01$

medication purpose. This pattern enabled us to evaluate predictions of the P-K model.

\section{PC and HK Predict Health Literacy}

Guided by the P-K model, multiple regressions were conducted to examine the interplay between PC and $\mathrm{HK}$ as predictors of health literacy among adults with diabetes, as we have done for adults with hypertension. ${ }^{19,20} \mathrm{We}$ adopted a stepwise approach to enter the correlates of health literacy in three steps: (1) age and education, (2) PC and HK, and (3) the interaction term of $\mathrm{PC}$ and $\mathrm{HK}$. All measures were centered to reduce collinearity in the regression models. For the first model $\left(F(2,668)=81.85, p<.001\right.$, adjusted $R^{2}=0.19, \mathrm{SE}=$ $0.90)$, education showed a significant association with health literacy $(B=0.44, t=12.74, p<.001)$.

For the second model $(F(4,666)=61.99, p<.001$, adjusted $R^{2}=0.27, \mathrm{SE}=0.86$ ), after adding PC and HK to the model, age, education, PC, and $\mathrm{HK}$ were all significantly associated with health literacy (Table 2). Age became significant after entering PC and HK (model 1: $B=0.06, t=1.58, p=0.11$ to model 2: $B=0.15, t=4.12, p<.001)$, in part due to shared variance among the three variables. However, the collinearity among the variables was within acceptable ranges (variance inflation factors (VIF) of age, PC, and HK in models 2 and 3 are $1.13,1.26$, and 1.08 respectively.) Notably, in the third model $\left(F(5,665)=56.08, p<.001\right.$, adjusted $R^{2}=0.29, \mathrm{SE}=$ $0.84)$, there was a significant interaction between $\mathrm{PC}$ and HK $(B=-0.16, t=-4.90, p<.001)$. The findings revealed an interactive contribution of $\mathrm{PC}$ and $\mathrm{HK}$ to health literacy, replicating the pattern found for $\mathrm{PC}$ and $\mathrm{HK}$ on health literacy among patients with hypertension. ${ }^{19}$
We conducted a simple slopes analysis ${ }^{32}$ to decompose the interaction of $\mathrm{PC}$ and $\mathrm{HK}$ into the simple regressions of $\mathrm{PC}$ on health literacy at different levels of HK (shown in Fig. 2). Among participants with lower HK, health literacy increased with PC. However, participants with higher HK showed equivalent health literacy regardless of their PC. This pattern suggests that HK compensates for declines in PC in contributing to health literacy. ${ }^{20}$

3. Association between Health Literacy and Medication Purpose

Most importantly, we examined the relationship between memory for medication purpose and health literacy, and whether this relationship could be accounted for by PC and HK. We conducted multiple regressions to examine the correlates of memory for medication purposes to evaluate whether the pre-conditions for mediation analysis (association between health literacy and memory reflects PC and HK) were met. We used a stepwise approach to enter the correlates: (1) age and education, (2) PC and HK, and (3) health literacy. All measures were centered to reduce the collinearity in the regression models. As shown in Table 3, in the first model $\left(F(2,668)=20.24, p<.001\right.$, adjusted $R^{2}=$ $0.05, \mathrm{SE}=0.97)$, age and education were significantly associated with medication purpose: Younger and more educated participants better remembered the purpose of their medications. In the second model $(F(4,666)=21.76$, $p<.001$, adjusted $R^{2}=0.11, \mathrm{SE}=0.94$ ), after adding $\mathrm{PC}$ and $\mathrm{HK}$ to the model, age, education, $\mathrm{PC}$, and $\mathrm{HK}$ were all significantly associated with medication purpose: Adults with better PC and HK better remembered medication

Table 2 Correlates of Health Literacy

\begin{tabular}{|c|c|c|c|c|c|c|}
\hline & Model 1 & & Model 2 & & Model 3 & \\
\hline & $\begin{array}{l}\boldsymbol{F} \\
81.85^{*}\end{array}$ & & $\begin{array}{l}\boldsymbol{F} \\
61.99 *\end{array}$ & & $\begin{array}{l}\boldsymbol{F} \\
56.08 *\end{array}$ & \\
\hline & $B$ & $t$ & $\boldsymbol{B}$ & $t$ & $B$ & $t$ \\
\hline Age & 0.06 & 1.58 & 0.15 & $4.12^{*}$ & 0.15 & $4.19 *$ \\
\hline Education & 0.44 & $12.74 *$ & 0.36 & $10.45^{*}$ & 0.35 & $10.25^{*}$ \\
\hline $\mathrm{PC}$ & & & 0.23 & $6.17 *$ & 0.22 & $6.16^{*}$ \\
\hline HK & & & 0.15 & $4.21 *$ & 0.11 & $3.18^{*}$ \\
\hline PC x HK & & & & & -0.16 & $-4.89 *$ \\
\hline
\end{tabular}

$* p<0.05$ 


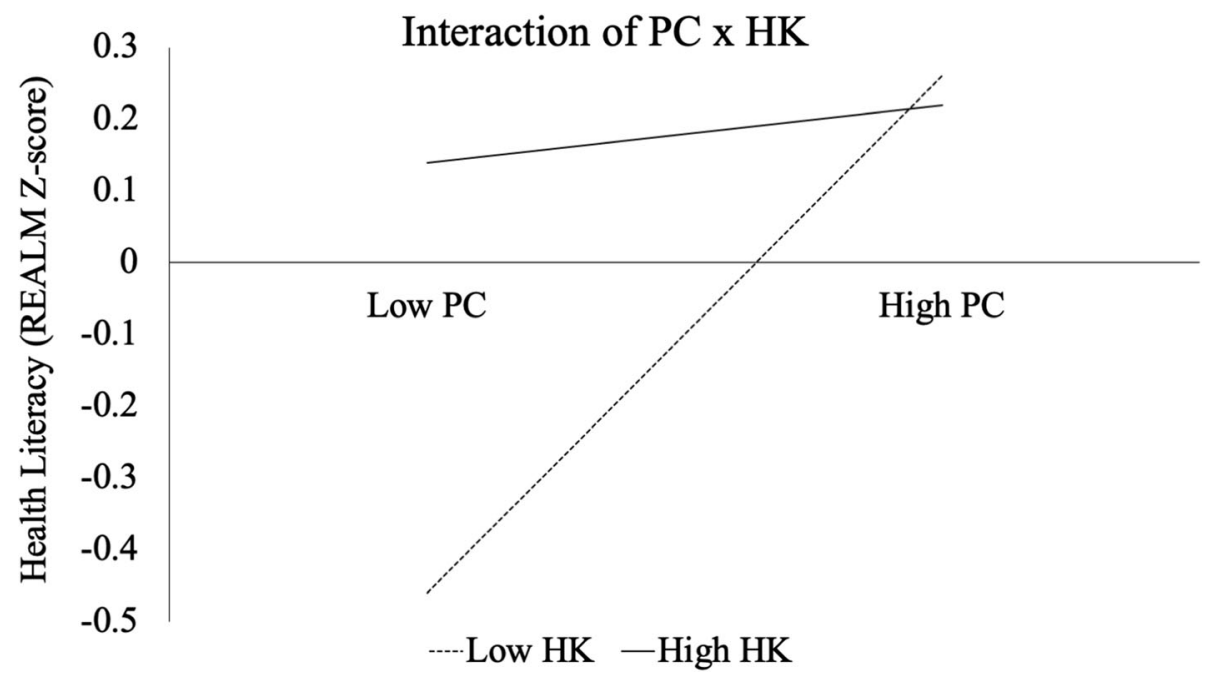

Figure 2 Interaction effects of processing capacity (PC) and health knowledge (HK) on health literacy (REALM, Z-score).

purpose. In the final model $(F(5,665)=18.97, p<.001$, adjusted $\left.R^{2}=0.12, \mathrm{SE}=0.94\right)$, age, $\mathrm{PC}, \mathrm{HK}$, and health literacy were all associated with memory for medication purpose. In addition to education, PC, and HK, adults with higher health literacy showed more accurate memory.

4. Mediating the Link between Health Literacy and Memory for Medication Purpose

As shown in Table 3, health literacy was associated with memory for medication purpose, so we conducted a mediation analysis to evaluate whether PC and HK helped explain the link between health literacy and memory for medication purposes (Fig. 3). The results suggest that the association between health literacy and medication purpose reflected in part significant indirect effects through PC and HK on medication purpose. However, there was still a direct effect of health literacy on medication purpose.

\section{DISCUSSION}

We examined relationships between memory for medication purpose and health literacy among adults with type II diabetes.

Table 3 Model Parameters for Medication Purpose, a Measure of Actionable Memory for Medication Taking

\begin{tabular}{lllllll}
\hline \hline & $\begin{array}{l}\text { Model } \\
\mathbf{1}\end{array}$ & & $\begin{array}{l}\text { Model } \\
\mathbf{2}\end{array}$ & & \multicolumn{3}{l}{$\begin{array}{l}\text { Model } \\
\mathbf{3}\end{array}$} \\
& $\boldsymbol{F}$ & & $\boldsymbol{F}$ & & $\boldsymbol{F}$ & \\
& $20.24^{*}$ & & $21.76^{*}$ & & $18.97^{*}$ & \\
& $\boldsymbol{B}$ & $\boldsymbol{t}$ & $\boldsymbol{B}$ & $\boldsymbol{t}$ & $\boldsymbol{B}$ & $\boldsymbol{t}$ \\
Age & -0.19 & - & -0.13 & - & -0.15 & - \\
& & $5.09^{*}$ & & $3.36^{*}$ & & $3.75^{*}$ \\
Education & 0.14 & $3.67^{*}$ & 0.07 & $1.92^{*}$ & 0.03 & 0.79 \\
PC & & & 0.12 & $3.04^{*}$ & 0.10 & $2.36^{*}$ \\
HK & & & 0.20 & $5.21^{*}$ & 0.18 & $4.74^{*}$ \\
HL & & & & & 0.11 & $2.65^{*}$ \\
\hline$* p<0.05$ & & & & & &
\end{tabular}

Knowing the purpose of medications is central to knowing how to take the medications as part of managing diabetes, especially because such patients often take many medications. According to the P-K model, health literacy depends on broader cognitive abilities that influence understanding and making decisions about self-care, including medication management. In support of this model, health literacy was found to be associated with recall of information needed for self-care among older adults with hypertension, and this association was mediated in part by $\mathrm{PC}$ and $\mathrm{HK} .{ }^{19-21}$ In the present study, we found that PC and HK also predicted health literacy among adults with diabetes. Moreover, these measures helped to explain the relationship of health literacy to memory for medication purposes. These findings expand previous literature to demonstrate the relationship between health literacy and actionable memory of medication taking beyond merely remembering facts about self-care of chronic illness.

Previous studies also suggest PC and HK interact to influence understanding health information, with $\mathrm{HK}$ helping to offset PC constraints on comprehension and memory among patients with hypertension. ${ }^{19,20}$ In the present study, we extend this finding to adults with diabetes, showing that $\mathrm{HK}$ similarly moderated the effects of PC on health literacy. PC did not associate with health literacy among those with more HK. Collectively, these findings suggest that knowledge can compensate for PC limits to underpin self-care.

Expanding earlier studies, ${ }^{33}$ health literacy predicted memory for self-care information (e.g., memory for medication purpose) even after controlling for the effects of age, PC, and $\mathrm{HK}$. This finding suggests that health literacy measures tap into other variables that influence memory for self-care information, perhaps including patients' beliefs about their illness (illness representation). ${ }^{34,35}$ Future research should address other factors that may contribute to health literacy, and in turn influence the self-care of illness. 


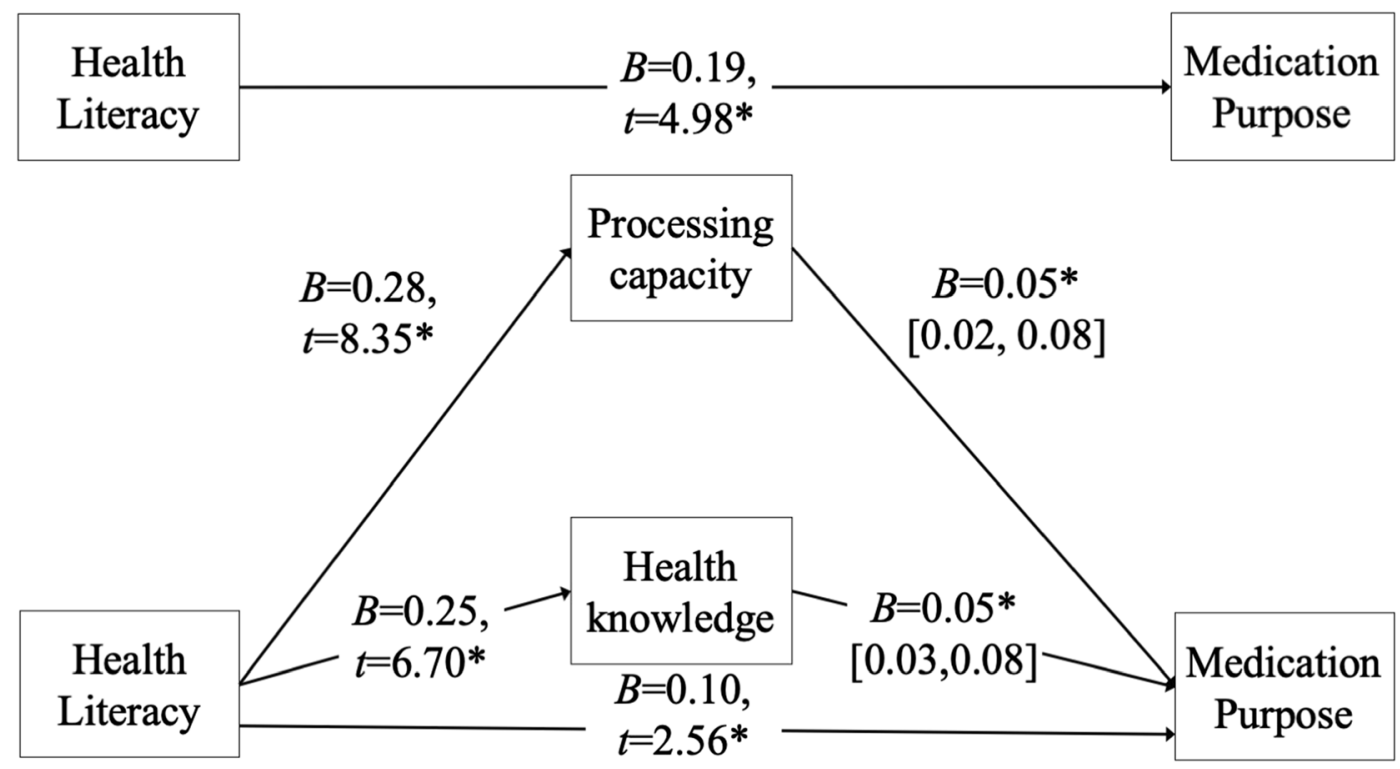

Figure 3 Processing capacity and health knowledge as the mediators of the association between health literacy and memory for medication purpose $(* p<.05)$.

Our findings help explain the role of health literacy in selfcare and suggest how to improve health outcomes. First, the study extends the picture of health literacy and self-care. Our earlier work with older adults with hypertension suggests health literacy influences health behaviors and outcomes in part by improving memory for information needed for selfcare, as better memory for health information predicts adherence. ${ }^{1}$ The present study extends these findings by showing that health literacy is associated with memory for self-care tasks such as taking medication. The impact of health literacy on recall and task knowledge in turn can be partly explained in terms of the effects of PC and HK on the efficiency and accuracy of comprehension and memory processes. ${ }^{36}$

A second implication of our results stems from the finding that knowledge helped to compensate for PC constraints. Theoretically, this finding suggests that good health literacy can be achieved in different ways. Patients may rely on HK in the face of very limited PC (e.g., older adults who have a chronic illness for many years may have more HK but increasingly diminished PC) ${ }^{34}$, or they may rely more on PC in the absence of HK (e.g., younger adults recently diagnosed with an illness may use domain-general PC more than HK).

This study has implications for improving memory for medication purposes, which should result in better medication adherence. ${ }^{3,9,12}$ We suggest improving memory for medication purpose by lowering the demands on PC and leveraging HK during medication taking. Strategies for reducing PC demands associated with learning about the purpose of prescribed medications include describing the purpose on prescription bottle labels and encouraging providers to mention purpose when telling patients how to take medication. Strategies for building on patient knowledge include describing the purpose of the medication in terms of its role in illness treatment. Leveraging prior knowledge to learn about the medications may facilitate memory for medications as well as building a coherent representation of illness, which is critical to medication adherence. ${ }^{5,6}$ Future studies should explore the relations between health literacy and different aspects of medication knowledge, such as the procedural knowledge of medication taking, and the connections to long-term medication adherence outcome.

Acknowledgments: We thank Thembi Conner-Garcia, Kathryn Davis, Anna Madison, Stacey McKeever, and Darcie Moeller for their help in conducting the study. The data used in this paper were collected as part of the baseline of a randomized controlled trial (RCT) study (ClinicalTrials.gov NCTO1296633). The results from the RCT study are described in Graumlich et al. (2016).

Corresponding Author: Jessie Chin, Ph. D.; University of Illinois at Urbana-Champaign, Champaign, IL, USA (e-mail: chin5@illinois.edu).

Funding This research was supported by a grant from the National Institutes of Health, 1R01NR011300.

\section{Compliance with ethical standards:}

Conflict of Interest: None declared.

Disclaimer: Any opinions, findings, and conclusions or recommendations expressed in this publication are those of the authors and do not necessarily reflect the views of the NIH.

\section{REFERENCES}

1. McPherson ML, Smith SW, Powers A, Zuckerman IH. Association between diabetes patients' knowledge about medications and their blood glucose control. Res Soc Adm Pharm RSAP. 2008;4(1):37-45. https://doi. org/10.1016/j.sapharm.2007.01.002

2. Okuyan B, Sancar M, Izzettin FV. Assessment of medication knowledge and adherence among patients under oral chronic medication treatment in community pharmacy settings. Pharmacoepidemiol Drug Saf. 2013;22(2):209-214. https://doi.org/10.1002/pds.3275 
3. Sweileh WM, Zyoud SH, Abu Nab'a RJ, et al. Influence of patients' disease knowledge and beliefs about medicines on medication adherence: findings from a cross-sectional survey among patients with type 2 diabetes mellitus in Palestine. BMC Public Health. 2014;14:94. https:// doi.org/10.1186/1471-2458-14-94

4. Toren O, Kerzman H, Koren N, Baron-Epel O. Patients' Knowledge Regarding Medication Therapy and the Association with Health Services Utilization. Eur J Cardiovasc Nurs. 2006;5(4):311-316. https://doi.org/ 10.1016/j.ejcnurse.2005.12.001

5. Broadbent E, Donkin L, Stroh JC. Illness and Treatment Perceptions Are Associated With Adherence to Medications, Diet, and Exercise in Diabetic Patients. Diabetes Care. 2011;34(2):338-340. https://doi.org/10.2337/ dc10-1779

6. Krauskopf K, Federman AD, Kale MS, et al. Chronic Obstructive Pulmonary Disease Illness and Medication Beliefs are Associated with Medication Adherence. COPD. 2015;12(2):151-164. https://doi.org/10. 3109/15412555.2014.922067

7. Morrow DG, Carver LM, Leirer VO, Tanke ED. Medication Schemas and Memory for Automated Telephone Messages. Hum Factors 2000;42(4):523-540. https://doi.org/10.1518/001872000779698042

8. Morrow DG, Leirer VO, Andrassy JM, Tanke ED, Stine-Morrow EAL. Medication Instruction Design: Younger and Older Adult Schemas for Taking Medication. Hum Factors. 1996;38(4):556-573. https://doi.org/ 10.1518/001872096778827305

9. Kuntz JL, Safford MM, Singh JA, et al. Patient-centered interventions to improve medication management and adherence: a qualitative review of research findings. Patient Educ Couns. 2014;97(3):310-326. https://doi. org/10.1016/j.pec.2014.08.021

10. Morrow DG, Leirer VO, Carver LM, Tanke ED. Older and younger adult memory for health appointment information: Implications for automated telephone messaging design. J Exp Psychol Appl. 1998;4(4):352-374. https://doi.org/10.1037/1076-898X.4.4.352

11. Persell SD, Heiman HL, Weingart SN, et al. Understanding of drug indications by ambulatory care patients. Am J Health-Syst Pharm AJHP Off J Am Soc Health-Syst Pharm. 2004;61(23):2523-2527. https://doi. org/10.1093/ajhp/61.23.2523

12. Scheibehenne B, Wilke A, Todd PM. Expectations of clumpy resources influence predictions of sequential events. Evol Hum Behav. 2011;32(5):326333. https://doi.org/10.1016/j.evolhumbehav.2010.11.003

13. U.S. Department of Health and Human services. Healthy People 2010: Understanding and Improving Health. 2nd ed. U.S. Government Printing Office; 2000. http://www.health.gov/healthypeople/. Accessed 13 Sept 2020

14. Mosher HJ, Lund BC, Kripalani S, Kaboli PJ. Association of health literacy with medication knowledge, adherence, and adverse drug events among elderly veterans. $J$ Health Commun. 2012;17 Suppl 3:241-251 https://doi.org/10.1080/10810730.2012.712611

15. Al Sayah F, Majumdar SR, Williams B, Robertson S, Johnson JA. Health Literacy and Health Outcomes in Diabetes: A Systematic Review. J Gen Intern Med. 2013;28(3):444-452. https://doi.org/10.1007/s11606-0122241-Z

16. Berkman ND, Sheridan SL, Donahue KE, Halpern DJ, Crotty K. Low health literacy and health outcomes: an updated systematic review. Ann Intern Med. 2011;155(2):97-107. https://doi.org/10.7326/0003-4819155-2-201107190-00005

17. Du S, Zhou Y, Fu C, Wang Y, Du X, Xie R. Health literacy and health outcomes in hypertension: An integrative review. Int $J$ Nurs Sci Published online June 9, 2018. https://doi.org/10.1016/j.ijnss.2018. 06.001

18. van der Heide I, Uiters E, Rademakers J, Struijs JN, Schuit AJ, Baan CA. Associations Among Health Literacy, Diabetes Knowledge, and SelfManagement Behavior in Adults with Diabetes: Results of a Dutch Cross-Sectional Study. J Health Commun. 2014;19(sup2):115-131. https://doi.org/10.1080/10810730.2014.936989
19. Chin J, Morrow DG, Stine-Morrow EAL, Conner-Garcia T, Graumlich JF, Murray MD. The Process-Knowledge Model of Health Literacy: Evidence from a Componential Analysis of Two Commonly Used Measures. $J$ Health Commun. 2011;16(Suppl 3):222-241. https://doi.org/10.1080/ 10810730.2011.604702

20. Chin J, Payne B, Gao X, et al. Memory and comprehension for health information among older adults: Distinguishing the effects of domaingeneral and domain-specific knowledge. Memory. 2015;23(4):577-589. https://doi.org/10.1080/09658211.2014.912331

21. Levinthal BR, Morrow DG, Tu W, Wu J, Murray MD. Cognition and health literacy in patients with hypertension. J Gen Intern Med. 2008;23(8): 11721176. https://doi.org/10.1007/s11606-008-0612-2

22. Graumlich JF, Wang H, Madison A, et al. Effects of a Patient-Provider, Collaborative, Medication-Planning Tool: A Randomized, Controlled Trial. J Diabetes Res https://doi.org/10.1155/2016/2129838

23. Callahan CM, Unverzagt FW, Hui SL, Perkins AJ, Hendrie HC. Six-Item Screener to Identify Cognitive Impairment Among Potential Subjects for Clinical Research Med Care. 2002;40(9):771-781. https://doi.org/10. 1097/00005650-200209000-00007

24. Fillenbaum GG. Multidimensional Functional Assessment of Older Adults: The Duke Older Americans Resources and Services Procedures. Psychology Press. 1988.

25. Davis TC, Long SW, Jackson RH, et al. Rapid estimate of adult literacy in medicine: a shortened screening instrument. Fam Med. 1993;25(6):391-395.

26. Salthouse TA. Mediation of Adult Age Differences in Cognition by Reductions in Working Memory and Speed of Processing. Psychol Sci. 1991;2(3):179-183. https://doi.org/10.1111/j.1467-9280.1991. tb00127.x

27. Garcia AA, Villagomez ET, Brown SA, Kouzekanani K, Hanis CL. The Starr County Diabetes Education Study: Development of the Spanishlanguage diabetes knowledge questionnaire. Diabetes Care. 2001;24(1):16-21. https://doi.org/10.2337/diacare.24.1.16

28. Cohen J. Statistical Power Analysis for the Behavioral Sciences. Routledge. 2013

29. Fritz MS, MacKinnon DP. Required Sample Size to Detect the Mediated Effect. Psychol Sci. 2007;18(3):233-239. https://doi.org/10.1111/j.14679280.2007.01882.x

30. Baltes PB. On the incomplete architecture of human ontogeny: Selection, optimization, and compensation as foundation of developmental theory. Am Psychol. 1997;52(4):366-380. https://doi.org/10.1037/0003-066X. 52.4 .366

31. Beier ME, Ackerman PL. Age, ability, and the role of prior knowledge on the acquisition of new domain knowledge: promising results in a realworld learning environment. Psychol Aging. 2005;20(2):341-355. https:// doi.org/10.1037/0882-7974.20.2.341

32. Preacher KJ, Curran PJ, Bauer DJ. Computational Tools for Probing Interactions in Multiple Linear Regression, Multilevel Modeling, and Latent Curve Analysis. J Educ Behav Stat. 2006;31(4):437-448. https://doi.org/10.3102/10769986031004437

33. Chin J, Madison A, Gao X, et al. Cognition and Health Literacy in Older Adults' Recall of Self-Care Information. The Gerontologist. 2017;57(2):261-268. https://doi.org/10.1093/geront/gnv091

34. Duwe EA, Holloway BM, Chin J, Morrow DG. Illness experience and illness representation among older adults with hypertension. Health Educ J. 2018;77(4):412-429. https://doi.org/10.1177/0017896917751553

35. Leventhal H, Safer MA, Panagis DM. The Impact of Communications on the Self-Regulation of Health Beliefs, Decisions, and Behavior. Health Educ Q. 1983;10(1):3-29. https://doi.org/10.1177/ 109019818301000101

36. Kintsch W. Comprehension: A Paradigm for Cognition. Cambridge University Press. 1998.

Publisher's Note: Springer Nature remains neutral with regard to jurisdictional claims in published maps and institutional affiliations. 